\title{
Which Factors Determine Our Online Social Capital? An Analysis Based on Structural Equation Modelling
}

\author{
Michael Grottke \\ GfK SE and Friedrich-Alexander-Universität Erlangen-Nürnberg \\ michael.grottke@fau.de
}

Janine Hacker

Friedrich-Alexander-Universität Erlangen-Nürnberg

\section{Carolin Durst}

Friedrich-Alexander-Universität Erlangen-Nürnberg

\section{Abstract}

The relationship between social network sites and social capital has received much research attention. However, two research gaps can be identified in the existing literature. First, only few studies have examined online social capital as a resource in online social networks. In this regard, it is not clear how to validly measure online social capital. Second, while the factors influencing social capital, among them properties of an individual's social network, have been investigated in offline settings, such factors have not yet been investigated in terms of online social capital. Addressing these gaps, we asked 1000 Facebook users to provide information on their Facebook usage and online friendship network. Employing structural equation modelling for analysing the survey data, we show that Williams' Internet Social Capital Scales, which are commonly used to assess social capital in offline settings, can be used to validly measure online social capital. Moreover, we find that some of the variables influencing offline social capital, among them similarity in terms of sociodemographic attributes, seem less important in an online setting.

Keywords: Social capital, Social networks, Structural modelling/Structural equation modelling (SEM)

\section{Introduction}

Our social network influences the way we think, feel, and interact within the society (Christakis \& Fowler, 2013). People we are connected to provide us with information and advice, they support us emotionally in times of crisis, or they lend us funds when we face temporary financial problems (Rostila, 2011). The resources that we can access through our social network to obtain these benefits are referred to as social capital (Lin, 2001b). Our social networks carry different types of social capital. Bonding social capital is closely related to thick trust (Anheier \& Kendall, 2002), and it provides emotional support. Bridging social capital, on the other hand, connects heterogeneous people across social groups and provides access to sets of non-redundant resources.

The impact of properties of an individual's social network (such as the extent to which someone interacts with people highly similar to him-/herself) on social capital has received a lot of attention in "purely" offline settings. With the rise of social network sites (SNS), social capital has also become a prominent theme in the fields of computer-mediated communication and online social media research. Against this background, the Internet Social Capital Scales (ISCS) were developed (Williams, 2006). Although designed for measuring social capital in 
online as well as offline contexts, the ISCS have mostly been applied to investigate offline social capital. In fact, they are the predominantly-used survey tool in studies examining the influence of the use of SNS on social capital in localised offline settings (Burke, Kraut, \& Marlow, 2011; Burke, Marlow, \& Lento, 2010; Ellison, Steinfield, \& Lampe, 2007; Steinfield, Ellison, \& Lampe, 2008; Yoder \& Stutzman, 2011), e.g., campus life. Hence, it remains unclear whether Williams' ISCS can actually be applied for validly measuring online social capital.

Furthermore, a gap exists regarding the antecedents of online social capital. It is not clear how different attributes of our online friendship network, e.g., on Facebook, relate to the formation of bonding and bridging social capital in this online setting. While the connections may mirror the ones of our offline network, SNS enable different and more varied means of communication, e.g., for maintaining weaker connections with acquaintances. Moreover, we are confronted with various information about our friends' friends, which may lead to the conversion of "latent" connections into explicit linkages (e.g., Ellison, Steinfield, \& Lampe, 2011). Besides testing the validity of Williams' ISCS in terms of assessing online social capital, our article hence focuses on the following research question: What are the factors that influence online social capital?

To answer our research question, a sample of 1000 Facebook users was retrieved from the online panel of the Gesellschaft für Konsumforschung (GfK, Germany's largest market research institute). In an online survey, we collected information on the survey participants' Facebook usage, network structure, network ties, and network friends. In addition, the participants were required to give us access to their Facebook data, including information on their own gender and age as well as the number of Facebook friends, by installing a Facebook application.

Employing structural equation modelling for analysing the survey data, we found that Williams' ISCS can be used to validly measure online social capital. Moreover, our analysis indicates some of the variables influencing offline social capital, among them similarity in terms of sociodemographic attributes, to be less important in an online setting.

With this article, we contribute to online social media research by validating the ISCS in an online setting and identifying a set of factors influencing online social capital. Our study design addresses further methodological shortcomings of the existing literature. Firstly, as compared to previous investigations (Burke et al., 2010; Ellison, Lampe, Steinfield, \& Vitak, 2010; Steinfield et al., 2008) that relied on samples of university students, our study uses a more diverse and hence more representative selection. Secondly, other researchers (e.g., Ellison et al., 2007) employed reduced variants of the bonding and bridging social capital scales, while we apply the full 20 questions from Williams' original ISCS. Thirdly, our structural equation model combines aspects of both confirmatory factor analysis and regression analysis. Doing so leads to more accurate results concerning online social capital and the variables affecting it as compared to previous studies that rely on a two-step approach to investigate the influence of online social networks on (offline) social capital.

The remainder of the article is structured as follows. After discussing the theoretical background concerning the concept of social capital, we present related work on the relationships between SNS and social capital. Based on this foundation, we develop our research model, describe how the data were collected and analysed, and discuss our findings. The article closes with concluding remarks, pointing to areas of our future research. 


\section{Social Capital: Conceptualisation and Measurement}

Social capital can be defined as the resources that are embedded in one's social network and that can be accessed or mobilised through ties in the network (Lin, 2001b, p. 29). Rooted deeply in the social sciences (Hyyppä, 2010), social capital theory has been employed to explain different societal phenomena. For instance, it has been studied as a determinant of public health in medical sociology (Marmot \& Wilkinson, 2005), as a predictor of civil engagement in political science (Putnam, 2001) and as a factor influencing team cohesiveness and project success in organisational science (Chua, Lim, \& Soh, 2012).

Social capital is associated with different types of resources, which can be classified into four categories (Rostila, 2011):

- Informational support refers to information, knowledge and advice circulating in the network.

- Emotional support ensures that persons feel loved, admired, and respected.

- Instrumental support describes help with tangible needs, e.g., money.

- Appraisal support refers to assistance with decision-making or giving feedback.

Enabling a greater sense of belonging, access to information and affective support, social capital is often associated with positive outcomes. However, it has been suggested that specific network structures could contribute to an unequal distribution of social resources across networks (Rostila, 2011). Drawing on the work on the potential downsides of social capital (Portes, 1998), it has further been argued that closed networks might limit an individual's access to socially-valued resources, and might contribute to the exchange of "bad social capital" by producing and maintaining negative norms and behaviours within networks (Rostila, 2011).

Social capital is commonly distinguished into bonding and bridging social capital (Putnam, Leonardi, \& Nanetti, 1994). Bonding social capital overlaps with the idea of strong ties. Being inward-looking, it is based on networks of very similar individuals with strong connections among each other. Usually, bonding social capital is provided by close friends, family members, or neighbours (Stone \& Hughes, 2002). On the other hand, bridging social capital is outward-looking, and it is based on heterogeneous networks with weak ties (Granovetter, 1973). While bonding social capital supports individuals in "getting by" in life, bridging social capital helps individuals to "get ahead", providing better opportunities for the achievement of informational and instrumental resources. Yet, not all bridging links are equally useful (Lin, 2001a). In the case of job seeking, for instance, a weak-tie contact may be particularly valuable if the contact person is in a more influential and powerful position than the job seeker (Avenarius, 2010).

Individual social capital in offline contexts is commonly measured using one of the following three survey instruments (Van Der Gaag \& Webber, 2008):

- The name generator estimates the network size and identifies the respondent's social network structure and content (Van Der Gaag \& Webber, 2008).

- The position generator is based on the assumption that occupations of network members reflect social resources and that highly-ranked occupations correspond with large returns (Van Der Gaag \& Webber, 2008). As such, the position generator measures the 
highest accessed prestige, range in accessed prestige as well as the number of different positions accessed.

- When using the resource generator, the respondent's access to social resources is checked against a list of useful and concrete resources (Van Der Gaag \& Webber, 2008). Afterwards, the respondent provides information on relationships to people having these resources (family members, friends, and acquaintances).

Focussing on the measurement of bridging and bonding social capital, the ISCS (Williams, 2006) can be applied to online as well as offline contexts. The measurement tool consists of a bridging and a bonding social capital sub-scale based on the criteria for the two social capital types (Putnam et al., 1994). Williams' ISCS are the predominantly-used survey tool in studies examining the influence of the use of SNS on social capital in localised offline settings (Burke et al., 2011, 2010; Ellison et al., 2007; Steinfield et al., 2008; Yoder \& Stutzman, 2011).

In this article, we do not aim to identify specific types of social resources, e.g., informational or emotional support. Rather, this article analyses whether Williams' ISCS can be used to validly measure the bonding and bridging social capital carried by online social networks. It further investigates the aspects of the online social network (as well as the individual attributes of the user) that influence the amount of bonding and bridging social capital attained. The focus of our research is depicted in Figure 1.

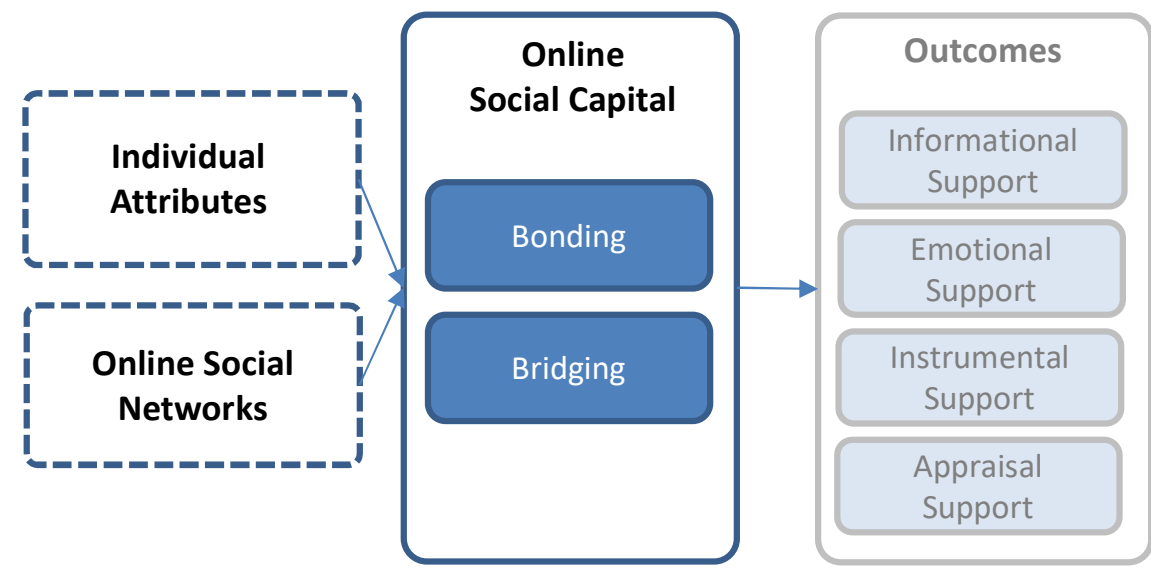

Figure 1. Focus of this Research

\section{Social Network Sites and Social Capital}

More than fifteen years ago, researchers were wondering whether or not "cybernetworks carry social capital" (Lin, 2001b, p. 214). It was suggested that the connections in the virtual world could lead to a rise of social capital due to the improved access to information for everyone (in theory, at least), as well as due to the increased ability of people to connect with fewer time and space constraints. Since these expectations were formulated in 2001, there has been a debate among scholars on how online interactions influence social capital. Summarising the body of literature on the subject, three major directions can be identified (Ellison et al., 2010).

1. Internet use allows people to generate new social capital, e.g., by triggering interactions with previously-unknown people.

2. Internet use decreases people's stock of social capital, e.g., by detracting people from face-to-face interaction. 
3. Internet use strengthens people's offline social network and supports social capital development, e.g., by supplementing traditional means of communication.

SNS play an important role in keeping in touch with the existing offline social network, and they are also useful for the development of new ties. Yet, most online ties are based on some kind of previous offline connection (Antoci, Sabatini, \& Sodini, 2011; Brandtzæg \& Nov, 2010; Ellison et al., 2007). SNS are regarded as particularly advantageous in that they allow users to create and maintain large and diffuse networks in a very convenient way, enabling cheap and easy communication with friends, even those in distant locations (Antoci et al., 2011). As social capital does not necessitate close friendships, even weak ties in SNS are likely to have a positive impact on social capital (Ellison et al., 2010).

A number of studies, primarily conducted using the SNS Facebook, have sought to identify the association between demographic factors, the intensity of SNS usage and the amount of bonding or bridging social capital. As mentioned before, most of them exclusively considered the impact of SNS use on social capital in a localised offline setting, such as campus life (Ellison et al., 2007; Steinfield et al., 2008; Yoder \& Stutzman, 2011).

As for the research design employed, most of the considered studies were cross-sectional in nature, and were based on questionnaires or surveys using student populations. Also, most studies adapted the ISCS (Williams, 2006) to assess bonding and bridging social capital, for instance at a university (Ellison et al., 2007; Steinfield et al., 2008; Yoder \& Stutzman, 2011), in one's general offline social network (Burke et al., 2011, 2010) or in the Facebook network (Jung, Gray, Lampe, \& Ellison, 2013). Only two studies (Brooks, Hogan, Ellison, Lampe, \& Vitak, 2014; Ellison, Vitak, Gray, \& Lampe, 2014) considered both general social capital, which is created through interactions with one's entire network, and Facebook-specific social capital, which is created through interactions with one's Facebook network.

With respect to demographic factors, older users of SNS were found to have lower levels of bonding social capital, but age did not impact bridging social capital (Burke et al., 2010; Steinfield, DiMicco, Ellison, \& Lampe, 2009). According to one study, women tended to experience more bonding social capital than men (Burke et al., 2010).

Regarding the relationship between Facebook usage and bonding social capital, studies have led to mixed results. A positive relationship between items related to Facebook use (i.e., the time spent on Facebook, the attitude towards Facebook, and the number of Facebook friends) and bonding social capital was identified based on a student sample (Ellison et al., 2007) as well as for employees using a corporate SNS (Steinfield et al., 2009). However, the existence of a significant relationship with bonding social capital could not be confirmed in later studies (Kwon, D'Angelo, \& McLeod, 2013; Vitak, Ellison, \& Steinfield, 2011). In addition to the frequency of SNS usage and structural properties of the network of Facebook friends, the way in which individuals use the SNS seems to play an important role. For instance, an increase in directed communication (such as wall posts and comments) is associated with a higher perceived bonding social capital (Burke et al., 2010). Researchers in the field of computermediated communication and online social media thus found Facebook use to have a limited impact on the creation and maintenance of bonding social capital (Burke et al., 2011; Ellison et al., 2007; Steinfield et al., 2008). Yet, the online social network is regarded as useful in that it provides another way for the interaction with strong ties, especially when face-to-face interaction is not feasible because close friends and family are geographically dispersed (Vitak et al., 2011). In a corporate context, bonding social capital has further been found to be 
predictable by the extent to which the internal SNS is used to connect with existing contacts (Steinfield et al., 2009). Bonding social capital turned out to be lower if the site is highly used to connect with new contacts.

With respect to bridging social capital, the literature agrees that Facebook use has a positive impact on the formation and enhancement of this kind of social capital, e.g., by allowing contact maintenance with a larger and more diverse group of acquaintances (Young, 2011). A strong association between Facebook usage intensity and bridging social capital could be identified (Ellison et al., 2007). The results of this cross-sectional study were confirmed by a follow-up project using longitudinal data (Steinfield et al., 2008), in other cross-sectional studies using student samples (Kwon et al., 2013; Vitak et al., 2011) as well as by a study in a corporate setting (Steinfield et al., 2009). Due to the identity information provided on a user's profile page, Facebook may be able to connect users with shared interests and encourage the conversion of latent ties into weak ties, which in turn increases bridging social capital (Ellison et al., 2011). Specifically, perceived bridging social capital appeared to be related to the number of Facebook friends (Burke et al., 2010). However, later empirical studies have shown that the total number of friends on Facebook does not predict bridging social capital, whereas the number of Facebook friends considered "actual" friends does (Ellison et al., 2011). In this regard, it is not enough to simply add connections; rather, it is necessary to engage in so-called Facebook relationship maintenance behaviours, i.e., activities that signal attention, create expectations of reciprocal attention or build trust (Brooks et al., 2014; Ellison et al., 2014). Furthermore, changes in particular communication elements on Facebook, such as the increased use of wall posts (Lee, Kim, \& Ahn, 2014; Yoder \& Stutzman, 2011) and more frequent receipt of messages from friends (Burke et al., 2011), are related to increases in bridging social capital.

Besides these empirical findings, other researchers have sought to identify network structure indicators to study and measure offline social capital (Australian Bureau of Statistics, 2004; Policy Research Initiative, 2005). In this regard, characteristics of the members were considered to study network diversity. In line with the conceptualisation of social capital (Putnam et al., 1994) and the idea behind survey instruments such as the position and resource generator (Van Der Gaag \& Webber, 2008), networks including members with similar profiles are thought to be associated with bonding relations. On the other hand, bridging relations emerge between individuals who are different from each other and are relatively more socially distant (Policy Research Initiative, 2005). Network diversity is measured by considering the social homogeneity of the network members, and is operationalised in terms of different dimensions of socioeconomic status, such as having the same first language, a similar ethnic background, roughly the same level of education, or a similar family income level (Australian Bureau of Statistics, 2004).

An overview of the empirical findings in the existing literature and the assumptions regarding the relationships between network diversity and the two forms of offline social capital is given in Table 1. Significantly positive, insignificant and significantly negative associations are denoted by " + ", "o" and "-", respectively. Assumptions (rather than empirical findings) are indicated by brackets. 


\begin{tabular}{|c|c|c|}
\hline Explanatory construct & Bonding social capital & Bridging social capital \\
\hline Gender $(0=$ "male", $1=$ "female" $)$ & $+:$ Burke et al. (2010) & \\
\hline Age & $\begin{array}{l}\text { - : Burke et al. (2010); } \\
\text { Steinfield et al. (2009) }\end{array}$ & \\
\hline $\begin{array}{l}\text { SNS Usage Intensity. } \\
\text { (*Daily time spent on the SNS) } \\
\left({ }^{*} \text { Attitude towards the SNS) }\right.\end{array}$ & $\begin{array}{l}+ \text { : Ellison et al. (2007); } \\
\text { Steinfield et al. (2009) } \\
\text { o : Kwon et al. (2013); } \\
\text { Vitak et al. (2011) }\end{array}$ & $\begin{array}{l}+ \text { : Ellison et al. (2007); } \\
\text { Kwon et al. (2013); } \\
\text { Steinfield et al. (2008); } \\
\text { Steinfield et al. (2009); } \\
\text { Vitak et al. (2011) }\end{array}$ \\
\hline ( Number of friends on the SNS) & & $\begin{array}{l}+: \text { Burke et al. }(2010) \\
\text { o : Ellison et al. }(2011)\end{array}$ \\
\hline $\begin{array}{l}\text { Extent to which SNS friends were } \\
\text { initially met on the SNS } \\
\end{array}$ & - : Steinfield et al. (2009) & \\
\hline $\begin{array}{l}\text { Extent to which real-life are also SNS } \\
\text { friends }\end{array}$ & $+:$ Steinfield et al. (2009) & \\
\hline Common mother tongue & \multirow{4}{*}{$\begin{array}{l}\text { (+): Australian Bureau of } \\
\text { Statistics (2004); } \\
\text { Policy Research Initiative } \\
(2005)\end{array}$} & \multirow{4}{*}{$\begin{array}{l}\text { (-): Australian Bureau of } \\
\text { Statistics (2004); } \\
\text { Policy Research Initiative } \\
\text { (2005) }\end{array}$} \\
\hline Similarity of ethnic background & & \\
\hline Similarity of educational background & & \\
\hline Similarity of household income & & \\
\hline
\end{tabular}

Table 1. Findings and Assumptions Concerning the Factors Determining (Offline) Social Capital

Addressing the gaps and the directions for further research, most of the reviewed papers suggest that future studies should look at more diverse populations and use longitudinal data to allow the determination of causal relationships (Bohn, Buchta, Hornik, \& Mair, 2014; Brooks et al., 2014; Ellison et al., 2014). As the measurement of social capital is still considered an issue, future research should also develop new metrics and validate the existing ones (Ellison et al., 2014).

\section{Model Development}

As shown in the last section, the existing literature has investigated the influence of various factors, such as the intensity of SNS usage, on offline bonding and bridging social capital. We will now draw on this previous work to explain which constructs were included in our study of the social capital inherent in the online social network maintained via Facebook, and how we operationalised them into variables.

\subsection{Online Social Capital}

We have already mentioned that other authors employed adaptations of the ISCS (Williams, 2006). For example, they used only five of the questions related to bonding social capital, and nine of the bridging-social-capital-related ones (Ellison et al., 2007). In contrast to this, we decided to make use of all ten questions for both the bonding and the bridging social capital scale, listed in Table 1 of the article introducing the ISCS (Williams, 2006), to find out whether these scales are actually appropriate for a purely online setting. To this end, we dropped the word "offline" in each question, and replaced "online" by an explicit reference to Facebook. As our study was conducted in Germany, all questions were translated into German. (Please refer to the Appendix for the original German questionnaire employed by us as well as an English version.) In our questionnaire, the 20 questions were grouped in five blocks; for each respondent the questions within a group were randomly ordered. Similar to the original article (Williams, 2006), all questions were formulated as statements, and the answers were measured 
on a five-point Likert scale from "strongly disagree" to "strongly agree". We also followed Williams in considering these variables to be metric.

As for the constructs potentially able to explain online social capital, we distinguish between individual attributes and aspects of the online social network. An overview of our discussion is given in Table 2, where constructs not included in previous studies are printed in italics.

\begin{tabular}{|l|l|l|}
\hline \multicolumn{1}{|c|}{ Group } & \multicolumn{1}{|c|}{ Explanatory construct } & \multicolumn{1}{c|}{ Variable name } \\
\hline \multirow{4}{*}{ Individual } & Gender & Gender \\
\cline { 2 - 3 } & Age & Age \\
\cline { 2 - 3 } & Duration of SNS membership & FBMem \\
\cline { 2 - 3 } & Daily time spent on the SNS & FBTim \\
\cline { 2 - 3 } & Attitude towards the SNS & FBAtt \\
\hline \multirow{5}{*}{$\begin{array}{l}\text { Online Social } \\
\text { Network }\end{array}$} & Number of friends on the SNS & \#FBF \\
\cline { 2 - 3 } & Extent to which SNS friends were initially met on the SNS & OnFBF \\
\cline { 2 - 3 } & Extent to which real-life friends are also SNS friends & RLFBF \\
\cline { 2 - 3 } & Extent to which SNS friends are considered close friends & CloFBF \\
\cline { 2 - 3 } & Common mother tongue & ComMT \\
\cline { 2 - 3 } & Similarity of ethnic background & SimEB \\
\cline { 2 - 3 } & Similarity of educational background & SimEd \\
\cline { 2 - 3 } & Similarity of household income & SimHI \\
\hline
\end{tabular}

Table 2. Explanatory Constructs and their Operationalisation in this Study

\subsection{Individual Attributes}

Similar to the existing literature, we hypothesise that the gender and the age of a person might affect his or her online social capital. We therefore included the variables Gender (with $0=$ "male" and 1 = "female") and Age (measured in years) in our model.

With respect to the constructs explaining bonding and bridging social capital, literature has focused on the SNS usage intensity, defined to be composed of various aspects (Ellison et al., 2007): the daily time spent on the SNS, the attitude towards the SNS, and the number of friends on the SNS. In fact, the first two aspects can be regarded as related to the individual him-/ herself. The influence of the number of friends on the SNS on bridging social capital was analysed separately only once (Burke et al., 2010). For our study, we decided to go a step further, and to distinguish between all aspects lumped together in the SNS usage intensity.

The variable FBTim in our model is based on the (translated) question referring to the average daily time spent on Facebook (Ellison et al., 2007), using the same six response categories. Similar to a previous study (Steinfield et al., 2008), we transformed these categories into a metric scale by assigning the score of the mid-point of each category. For example, the category "1-2 hours" was assigned the value 1.5 [hours]; for the category "more than 3 hours" we chose the value 7.5 [hours], implying a maximum of 12 hours spent on Facebook per day on the average.

In addition to the daily time spent on Facebook, we also investigate the duration of the Facebook membership as a possible explanatory variable for online bonding and bridging social capital. In the questionnaire, we made use of the question and the response categories defined in another German study (Kneidinger, 2010). However, we added a sixth category representing a Facebook membership exceeding four years. By assigning the midpoint to each 
category (using the value 5 [years] for the last category), we obtained the metric variable FBMem.

In our model, we include the latent variable FBAtt, representing the attitude towards Facebook, which was measured using the German translation (Kneidinger, 2010) of six attitudinal questions (Ellison et al., 2007). Again, a five-point Likert scale ranging from "strongly disagree" to "strongly agree" was employed for each response.

\subsection{Online Social Network}

All respondents were required to give us access to their Facebook network data. Therefore, we were able to easily measure the number of Facebook friends using a tool. Unlike other studies (such as Steinfield et al., 2009) we thus did not have to rely on self-reported and grouped data resulting from categories representing intervals (e.g., "51-100 Facebook friends"). The variable measuring the exact number of Facebook friends is named \#FBF in our model.

The above-mentioned study (Steinfield et al., 2009) also investigated whether or not the extent to which SNS friends were initially met on the SNS and the extent to which real-life friends are also SNS friends had any influence on the social capital. There, both constructs were measured on an ordinal scale from 1 (= "none") to 5 (= "a lot"), but they were treated as metric variables. For assessing our variables OnFBF (fraction of Facebook friends met online) and RLFBF (fraction of real-life friends who are also Facebook friends) via our questionnaire, we chose the categories "none", "few", "about half", "most" and "all". Based on these descriptions, it seems a natural choice to assign the values $0,0.25,0.5,0.75$ and 1 to the categories. This is equivalent to using the values 1 to 5 , which can be derived via a simple linear transformation. We feel that our names for the categories make it more justifiable to consider the variables to be metric.

Employing the same five categories from "none" to "all", we added five further variables to our analysis: the fraction of Facebook friends considered close friends (CloFBF), the fraction of Facebook friends with the same mother tongue (ComMT), the fraction of Facebook friends with a similar ethnic background (SimEB), the fraction of Facebook friends with a similar educational background (SimEd), and the fraction of Facebook friends with a similar household income (SimHI). The latter four variables have been derived based on the abovementioned publications arguing that networks with a higher degree of similarity tend to be associated with a higher bonding social capital but a lower bridging social capital (Australian Bureau of Statistics, 2004; Policy Research Initiative, 2005).

The overall structural equation model based on all described variables is depicted in Figure 2. It should be noted that our model includes both observable variables (drawn as rectangles) and latent variables (drawn as ovals). Previous work (e.g., Steinfield et al., 2009) proceeded as follows. First, an exploratory or confirmatory factor analysis was conducted to investigate the association between a latent construct (e.g., Bond) and the observable variables (e.g., Bond1Bond10). The latent construct was then estimated, for instance by simply averaging the scores of the related observable items. In a second step, these estimates were used to investigate the influence of the explanatory variables on the dependent variables with the help of a separate regression analysis. Our structural equation model does not necessitate such simplifying approximations, and it therefore leads to more accurate results.

Before trying to estimate the model parameters from real data, we need to make sure that none of the equations is underidentified. It is easily seen that for each of the 28 equations in our 
model the number of omitted system-exogenous variables is not smaller than the number of explanatory system-endogenous variables. The order criterion (von Auer, 2013, p. 589) thus indicates that all equations are exactly identified or overidentified, which is a necessary condition for the identifiability of the entire model. It is also possible to show that the sufficient rank criterion (von Auer, 2013, p. 603) is satisfied; therefore, all parameters can be estimated.

Our model structure implies that Bond and Brid could both be affected by all the explanatory constructs listed in Table 2. Technically, we will in each case test the null hypothesis that there is no influence of the respective explanatory variable on Brid (or Bond) to see whether this hypothesis can be rejected, indicating a significant relationship.

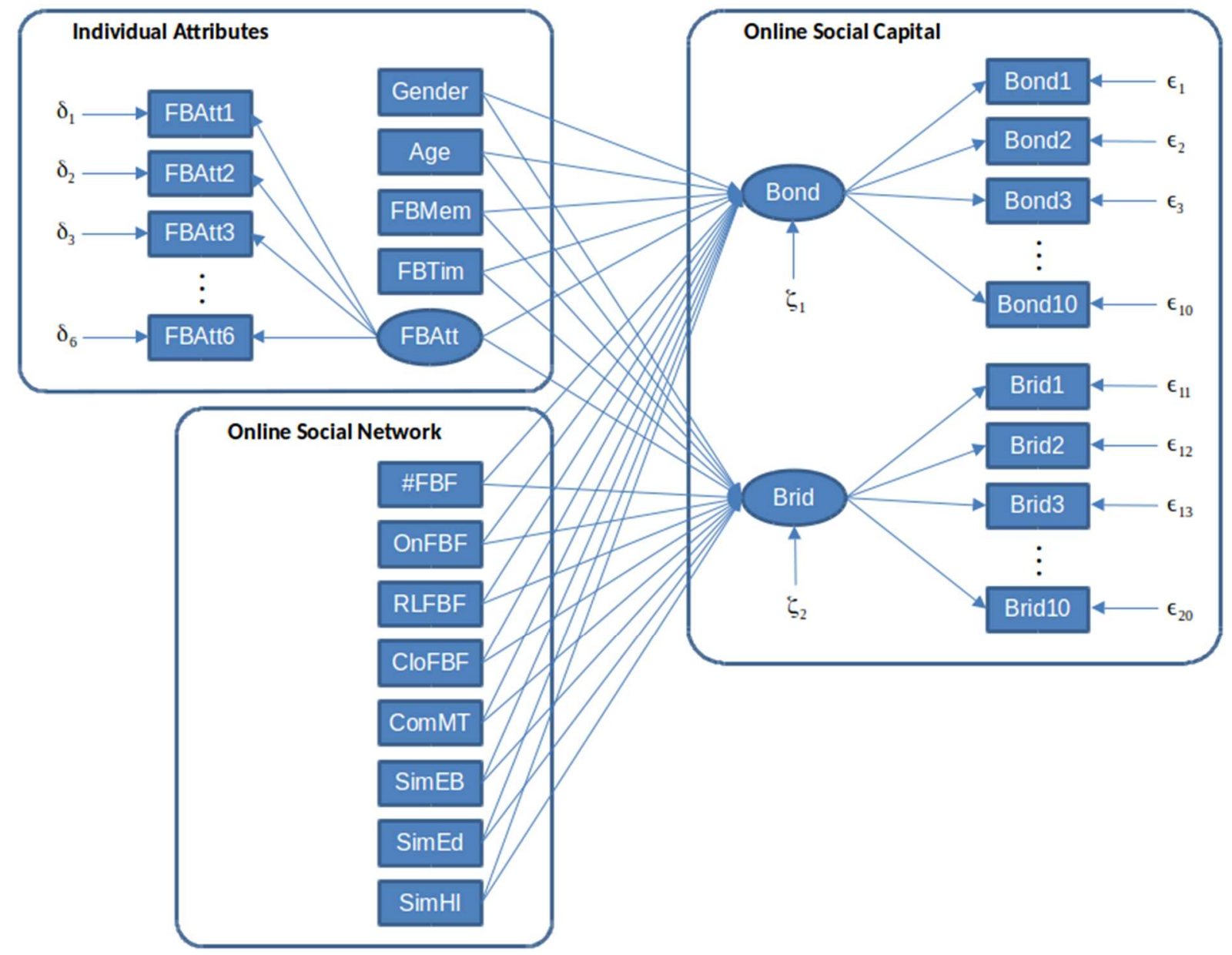

Figure 2. Structural Equation Model

\section{Data Collection and Statistical Analysis}

The participants of our study were drawn from the GfK Online Panel via an online survey fielded from May 5 until May 22, 2012. All participants were invited via an e-mail containing a short description of the study, some information about confidentiality and incentives, as well as a link to the online survey. Each participant was required to have a Facebook account and had to be willing to install a Facebook application giving us access to his/her network data. We applied a stratified sampling approach based on gender and age to guarantee a representative sample from the Facebook population. However, due to age restrictions in the GfK Online Panel, the age group "17 and younger" was underrepresented in the sample, while 
the age groups "18-24" and "25-34" were slightly overrepresented. The study was closed once 1000 persons had participated.

To ensure validity, not all 1000 observations were used in our analyses. We dropped those observations for which the credibility of responses was in doubt. As shown in Figure 3, the data cleaning process involved the exclusion of observations from our sample based on six criteria.

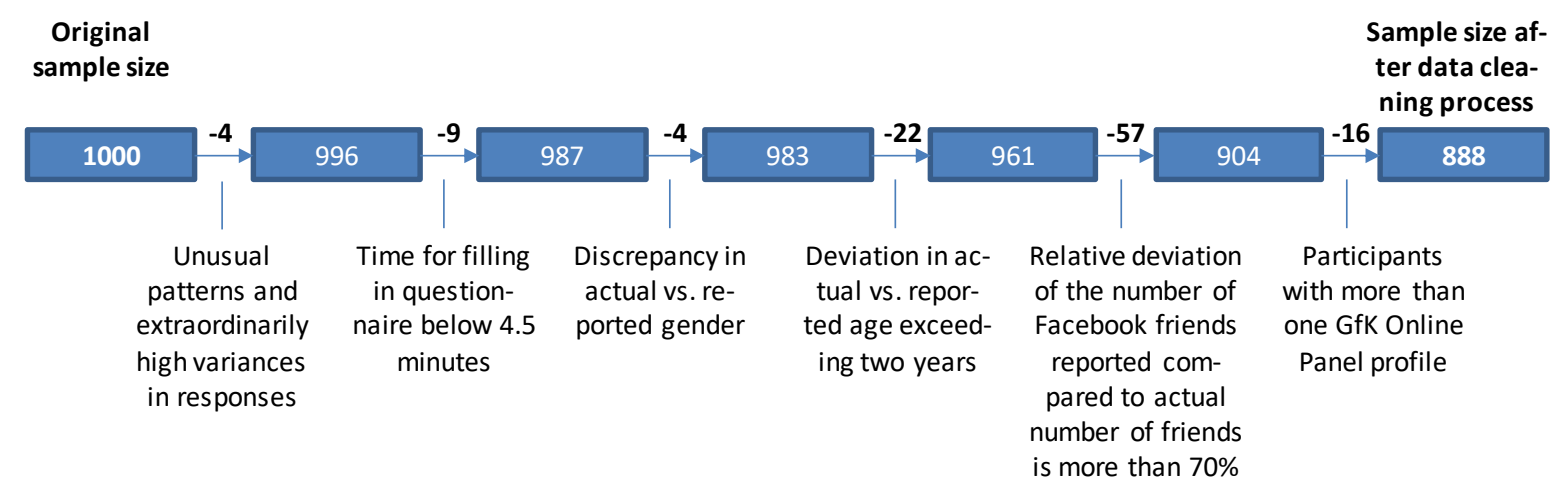

Figure 3. Data Cleaning Process

Four observations were excluded due to unusual patterns and an extraordinarily high variance in the responses. For nine observations the time taken by the respondents for filling in the questionnaire was less than four minutes and 30 seconds, which was considered too fast for thoroughly reading and answering the questions; therefore, these observations were dropped. Moreover, comparing each participant's responses on gender and age with information stored in the GfK Online Panel profile, we excluded four observations which showed a difference in gender and 22 data sets with a deviation in age exceeding two years. Furthermore, we calculated the relative deviation of the number of Facebook friends reported in the questionnaire based on the actual number of Facebook friends retrieved from the participant's Facebook network; we excluded 57 additional observations which showed a relative deviation of more than $70 \%$. Finally, we omitted 16 observations related to participants who turned out to have more than one GfK Online Panel profile. After this data cleaning process, 888 observations remained. In each case, we made use of the age given in the GfK Online Panel profile as well as of the actual number of Facebook friends extracted from the Facebook profile, to rely on the most exact information available. Table 3 compares the absolute and relative distribution of age and gender in our resulting data set with the one in the overall Facebook community (Czech, 2012). 


\begin{tabular}{|l|l|l|l|}
\cline { 2 - 4 } \multicolumn{1}{c|}{} & $\begin{array}{c}\text { Relative frequencies on } \\
\text { Facebook }\end{array}$ & $\begin{array}{c}\text { Relative frequencies in } \\
\text { our sample }\end{array}$ & $\begin{array}{c}\text { Absolute frequencies in } \\
\text { our sample }\end{array}$ \\
\hline Age (Years) & & & 54 \\
\hline 17 and younger & $16 \%$ & $6.1 \%$ & 271 \\
$18-24$ & $27 \%$ & $30.5 \%$ & 280 \\
$25-34$ & $27 \%$ & $31.5 \%$ & 141 \\
$35-44$ & $15 \%$ & $15.9 \%$ & 92 \\
$45-54$ & $10 \%$ & $10.4 \%$ & 32 \\
$55-64$ & $3 \%$ & $3.6 \%$ & 18 \\
\hline 65 and older & $2 \%$ & $2.0 \%$ & 888 \\
\hline Total & $100 \%$ & $100 \%$ & \\
\hline Gender & & & 427 \\
\hline Female & $48 \%$ & $48.1 \%$ & 461 \\
\hline Male & $52 \%$ & $51.9 \%$ & 888 \\
\hline Total & $100 \%$ & $100 \%$ & \\
\hline
\end{tabular}

\section{Table 3. Age and Gender Stratification}

Before continuing our analysis, we need to answer the question whether the $N=888$ observations available suffice for properly and accurately estimating the model shown in Figure 2 or whether this sample size should be considered excessive, leading to significant results even for tiny effects.

One important aspect to consider is $r$, the ratio of items to latent variables. While both a higher value of $r$ and a larger sample size $N$ improve estimation, there is a compensatory relation between $r$ and $N$ (Marsh, Hau, Balla, \& Grayson, 1998). From Monte Carlo simulations studying the robustness of estimating structural equation models in the context of confirmatory factor analysis (Boomsma, 1982), it can be inferred that for $r=3$ at least $N=200$ observations are required, while for $r=4$ a sample size of $N=100$ may suffice. These minimum sample sizes for $r=3$ and $r=4$ are also suggested by the results of a similar simulation study (Marsh et al., 1998), while for $r=2$ at least $N=400$ and for $r=12$ at least $N=50$ observations seem advisable.

Consolidating such findings, the following equation for determining the minimum sample size required has been suggested (Westland, 2010):

$$
N \geq 50 r^{2}-450 r+1100 .
$$

While this formula works nicely for $2 \leq r \leq 4$, interpolating the empirical results, the quadratic expression reaches its minimum at $r=4.5$ and then rises when further increasing $r$. For $r=12$, the minimum sample size computed amounts to 2900 , which is completely at odds with the above-mentioned findings.

We therefore propose the following continuous and differentiable function for approximating the sample size requirement:

$$
N \geq\left\{\begin{array}{cc}
50 r^{2}-450 r+1100 & \text { for } 2 \leq r \leq 4.45 \\
109.875-5 r & \text { for } 4.45<r \leq 12
\end{array}\right.
$$

Considering that there is a total of 26 items for the 3 latent variables in our model, the minimum number of observations required is thus calculated as 67 . 
However, the ratio $r$ is only one aspect on which the necessary sample size depends. The minimum effect to be identified in the analysis as well as the desired significance level and the power of the test should also be taken into consideration. Assuming that all observed variables follow a normal distribution, it has been shown (Westland, 2010, 2012) that the sample size required for detecting a minimum Gini correlation of size $\delta$ among $k$ latent variables in a test with significance level $\alpha$ and power $1-\beta$ can be calculated as

$$
N \geq \frac{1}{2 H}\left\{A\left(\frac{\pi}{6}-B+D\right)+H+\sqrt{\left[A\left(\frac{\pi}{6}-B+D\right)+H\right]^{2}+4 A H\left(\frac{\pi}{6}+\sqrt{A}+2 B-C-2 D\right)}\right\} .
$$

In this equation,

$$
A=1-\delta^{2}, \quad B=\delta \arcsin (\delta / 2), \quad C=\delta \arcsin (\delta), \quad D=\frac{A}{\sqrt{3-A^{\prime}}}, \quad H=\left(\frac{\delta}{\lambda_{1-\tilde{\alpha} / 2}-\lambda_{1-\beta}}\right)^{2},
$$

where $\lambda_{q}$ denotes the quantile of the standard normal distribution at level $q$, and $\tilde{\alpha}=1-(1-\alpha)^{2 / k(k-1)}$ is the significance level after Šidak correction. For correlations, $\delta$ values of 0.1, 0.3 and 0.5 represent a small, medium and large effect, respectively (Ellis, 2010, p. 41).

Based on a standard significance level of $5 \%$ and a power of $80 \%$, we would thus need minimum sample sizes of 290, 28 and 8 to detect small, medium and high correlations between our 3 latent variables according to Equation (2). (Of course, considering the ratio of items to latent variables, $N$ should never be smaller than 67 , as derived from Equation (1).)

It should be noted that all calculations assume normally-distributed variables. For Likert-scale data, as in our study, the sample size requirement may be two to three orders of magnitude larger due to non-normalcy (Westland, 2010). Nevertheless, this analysis suggests that our 888 observations are definitely not excessive and may suffice for identifying large effects.

Based on the available data, we estimated our structural equation model with the statistical tool R (R Core Team, 2018) and its sem package (Fox, 2006). We started out with a basic model containing parameters for all relationships indicated in Figure 2, as well as variance parameters for all disturbances. The variances of the latent variables FBAtt, Bond and Brid were set to one, to ensure identifiability. Following the modification indices calculated (Sörbom, 1989), we subsequently added a parameter for the covariance between Bond and Brid, 19 covariance parameters between pairs of items, as well as three covariances between an item and the related latent construct. The parameter estimation was conducted based on the variance-covariance matrix of the observable variables. To check whether or not the results are influenced by the different scales used for the various variables, we also carried out parameter estimation using the correlation matrix; however, the results proved to be stable. Also, the results were hardly affected when adding further covariance parameters.

Drawing on the visualisation of our model (Figure 2), Figure 4 illustrates the detected relationships between the investigated variables. In this regard, non-significant relationships are omitted, and those variables considered in our study for which none of the relationships with the dependent variables turned out to be significant are shown as white boxes with dashed frames. Significant relationships with a negative value of the estimated parameter are indicated by a minus sign above the directed edge. Those directed edges without a minus sign thus represent significant relationships with a positive estimated parameter. 
Providing more detailed insights, Table 4 lists the significant parameter estimates, omitting the (co-)variance parameters, and their related $p$ values. These $p$ values have been derived using the asymptotic distributions of the test statistics, which seems appropriate considering the large sample size of 888 . Moreover, the fifth entry in each row is the beta coefficient, showing by how many standard deviations the respective dependent variable is expected to increase or decrease if the related explanatory variable is increased by one standard deviation. For the two equations explaining Bond and Brid, unlike the original estimates these beta coefficients allow us to rank the explanatory variable according to their relative effect, which is the greater the larger the absolute value of the beta coefficient is. These ranks are listed in the sixth column of the table.

The overall goodness of fit of our model in terms of the root mean square error of approximation (RMSEA) amounts to 0.0586 . Literature agrees that an RMSEA exceeding 0.1 is not acceptable (Browne \& Cudeck, 1992; Schlittgen, 2009). While one of the two researchers who originally suggested the RMSEA metric considers the model fit to be good for values below 0.1 and very good for values below 0.05 (Steiger, 1989, p. 81), other authors think that an RMSEA value between 0.08 and 0.05 indicates a reasonable error of approximation (Browne \& Cudeck, 1992) or an adequate model fit (Schlittgen, 2009, p. 476). The overall ability of our model to represent the data can thus be considered satisfactory.

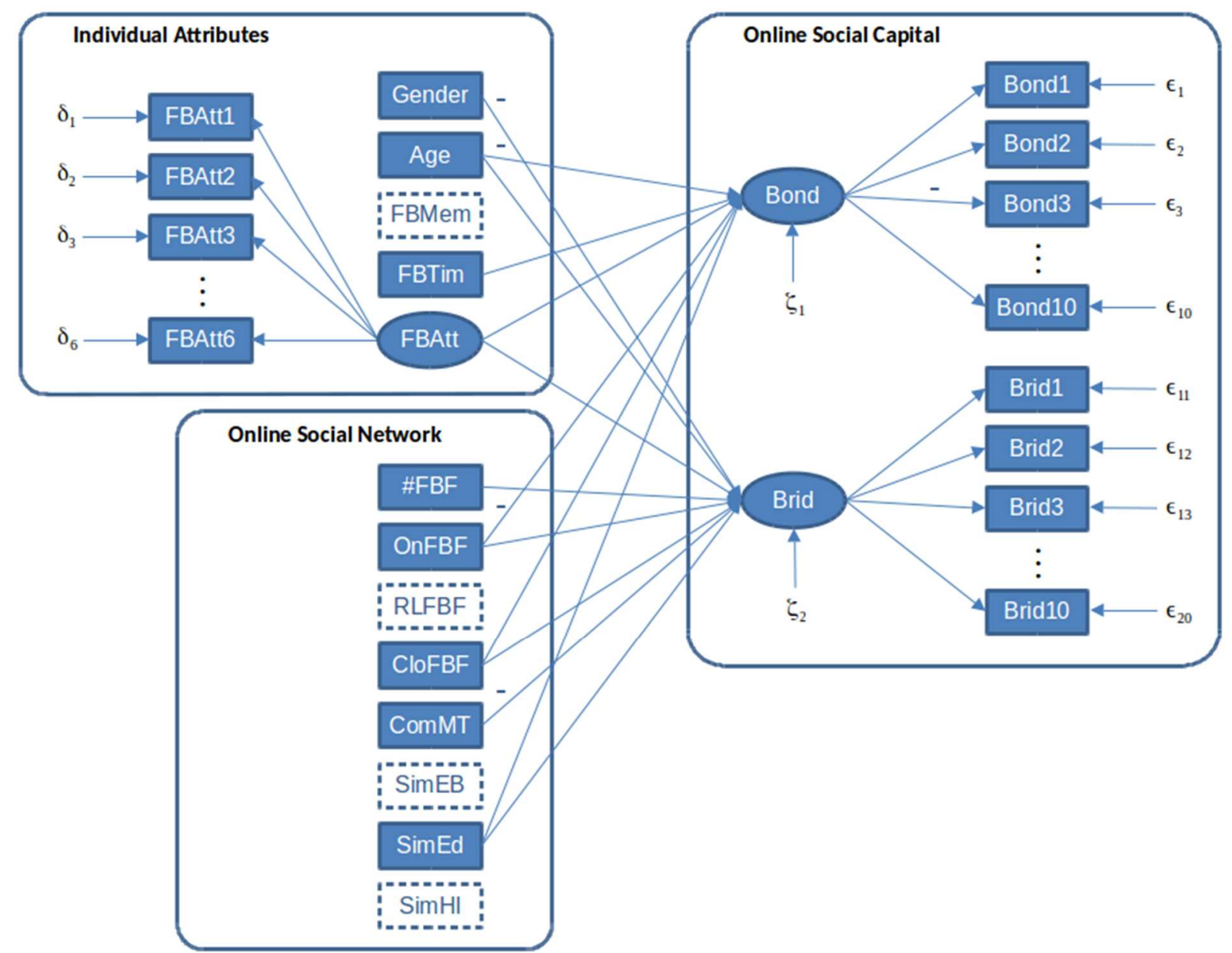

Figure 4. Significant Relationships in the Estimated Structural Equation Model 


\begin{tabular}{|c|c|c|c|c|c|}
\hline Group (Expl. Var.) & Expl. Var. $\rightarrow$ Dep. Var. & Estimate & p value & Beta Coeff. & Rank \\
\hline \multirow{10}{*}{$\begin{array}{l}\text { Online Social } \\
\text { Capital }\end{array}$} & Bond $\rightarrow$ Bond1 & 0.7805 & $8.0728 \cdot 10^{-136}$ & 1.0244 & \\
\hline & Bond $\rightarrow$ Bond2 & 0.7758 & $3.4317 \cdot 10^{-119}$ & 0.9004 & \\
\hline & Bond $\rightarrow$ Bond 3 & -0.3474 & $1.9594 \cdot 10^{-17}$ & -0.2575 & \\
\hline & Bond $\rightarrow$ Bond 4 & 0.8346 & $1.1627 \cdot 10^{-148}$ & 1.1745 & \\
\hline & Bond $\rightarrow$ Bond5 & 0.4197 & $1.6184 \cdot 10^{-23}$ & 0.3062 & \\
\hline & Bond $\rightarrow$ Bond6 & 0.6051 & $4.4996 \cdot 10^{-56}$ & 0.6924 & \\
\hline & Bond $\rightarrow$ Bond7 & 0.5561 & $1.0948 \cdot 10^{-71}$ & 0.6119 & \\
\hline & Bond $\rightarrow$ Bond 8 & 0.5101 & $2.2098 \cdot 10^{-63}$ & 0.5918 & \\
\hline & Bond $\rightarrow$ Bond9 & -0.2147 & $2.4067 \cdot 10^{-10}$ & -0.1869 & \\
\hline & Bond $\rightarrow$ Bond10 & 0.5072 & $1.0821 \cdot 10^{-55}$ & 0.5143 & \\
\hline \multirow{10}{*}{$\begin{array}{l}\text { Online Social } \\
\text { Capital }\end{array}$} & Brid $\rightarrow$ Brid1 & 0.5091 & $1.1006 \cdot 10^{-98}$ & 0.6581 & \\
\hline & Brid $\rightarrow$ Brid2 & 0.5409 & $5.3701 \cdot 10^{-118}$ & 0.8278 & \\
\hline & Brid $\rightarrow$ Brid3 & 0.5011 & $1.8901 \cdot 10^{-100}$ & 0.6714 & \\
\hline & Brid $\rightarrow$ Brid4 & 0.4941 & $1.0905 \cdot 10^{-87}$ & 0.5756 & \\
\hline & Brid $\rightarrow$ Brid5 & 0.5125 & $4.2903 \cdot 10^{-110}$ & 0.7125 & \\
\hline & Brid $\rightarrow$ Brid6 & 0.5412 & $1.2860 \cdot 10^{-115}$ & 0.8045 & \\
\hline & Brid $\rightarrow$ Brid7 & 0.4592 & $2.5636 \cdot 10^{-77}$ & 0.5117 & \\
\hline & Brid $\rightarrow$ Brid 8 & 0.4875 & $6.1073 \cdot 10^{-67}$ & 0.5937 & \\
\hline & Brid $\rightarrow$ Brid9 & 0.4482 & $6.5238 \cdot 10^{-80}$ & 0.5329 & \\
\hline & Brid $\rightarrow$ Brid10 & 0.4297 & $1.9892 \cdot 10^{-58}$ & 0.4913 & \\
\hline \multirow{6}{*}{$\begin{array}{l}\text { Individual } \\
\text { Attributes }\end{array}$} & FBAtt $\rightarrow$ FBAtt1 & 0.9175 & $2.4797 \cdot 10^{-125}$ & 1.0433 & \\
\hline & FBAtt $\rightarrow$ FBAtt2 & 0.6844 & $1.3061 \cdot 10^{-88}$ & 0.7938 & \\
\hline & FBAtt $\rightarrow$ FBAtt3 & 0.9560 & $1.1073 \cdot 10^{-142}$ & 1.1550 & \\
\hline & FBAtt $\rightarrow$ FBAtt 4 & 0.7660 & $2.2672 \cdot 10^{-95}$ & 0.8696 & \\
\hline & FBAtt $\rightarrow$ FBAtt5 & 0.9279 & $7.5468 \cdot 10^{-177}$ & 1.3873 & \\
\hline & FBAtt $\rightarrow$ FBAtt6 & 0.9025 & $5.1982 \cdot 10^{-128}$ & 1.0737 & \\
\hline \multirow{3}{*}{$\begin{array}{l}\text { Individual } \\
\text { Attributes }\end{array}$} & Age $\rightarrow$ Bond & -0.0171 & $5.7868 \cdot 10^{-7}$ & -0.2115 & 3 \\
\hline & FBTim $\rightarrow$ Bond & 0.0944 & $3.4035 \cdot 10^{-6}$ & 0.1829 & 4 \\
\hline & FBAtt $\rightarrow$ Bond & 0.4889 & $2.4958 \cdot 10^{-29}$ & 0.4889 & 1 \\
\hline \multirow{3}{*}{$\begin{array}{l}\text { Online Social } \\
\text { Network }\end{array}$} & OnFBF $\rightarrow$ Bond & -0.3883 & 0.0398 & -0.0797 & 6 \\
\hline & CloFBF $\rightarrow$ Bond & 1.1661 & $4.9037 \cdot 10^{-8}$ & 0.2131 & 2 \\
\hline & SimEd $\rightarrow$ Bond & 0.8647 & $7.553110^{-5}$ & 0.1619 & 5 \\
\hline \multirow{3}{*}{$\begin{array}{l}\text { Individual } \\
\text { Attributes }\end{array}$} & Gender $\rightarrow$ Brid & -0.2188 & 0.0055 & -0.1092 & 6 \\
\hline & Age $\rightarrow$ Brid & 0.0166 & $4.3625 \cdot 10^{-6}$ & 0.2054 & 3 \\
\hline & FBAtt $\rightarrow$ Brid & 1.2849 & $1.2326 \cdot 10^{-67}$ & 1.2849 & 1 \\
\hline \multirow{5}{*}{$\begin{array}{l}\text { Online Social } \\
\text { Network }\end{array}$} & $\# \mathrm{FBF} \rightarrow$ Brid & 0.0008 & 0.0026 & 0.1336 & 4 \\
\hline & OnFBF $\rightarrow$ Brid & 1.1426 & $1.9235 \cdot 10^{-8}$ & 0.2346 & 2 \\
\hline & CloFBF $\rightarrow$ Brid & 0.6024 & 0.0069 & 0.1101 & 5 \\
\hline & ComMT $\rightarrow$ Brid & -0.5097 & 0.0231 & -0.1049 & 8 \\
\hline & SimEd $\rightarrow$ Brid & 0.5645 & 0.0138 & 0.1057 & 7 \\
\hline
\end{tabular}

Table 4. Significant Parameter Estimates

\section{Discussion}

Our study was aimed at answering the question. What are the factors that influence online social capital?

In order to assess bonding and bridging social capital in an online setting, we used Williams' ISCS. Before we analysed the influencing factors, we validated those scales. Table 4 shows that all items supposed to measure a latent construct are loading significantly on the respective factor. This suggests that all items within each group are indeed measuring the same construct. 
The items Bond3 and Bond9 were designed to be reversed-scaled (Williams, 2006); this is correctly reflected in the negative loadings. However, the fraction of the overall variation within the items FBAtt1-FBAtt6 explained by FBAtt amounts to $53.7 \%$, while only $22.6 \%$ of the total variance of Bond1-Bond 10 and $19.1 \%$ of the variation in Brid1- Brid10 are explained by the related latent construct. This might indicate that there are further factors influencing the answers to the questions Bond1-Bond10 and Brid1-Brid10.

Regarding the factors influencing online social capital, the last 14 lines of Table 4 list the variables that were found to significantly affect online bonding social capital and online bridging social capital, respectively, as well as their ranks according to the strength of the relative effects. As already depicted in Figure 4, our analysis indicates significant influences of the variables FBAtt, Age, OnFBF, CloFBF and SimEd on both types of online social capital. While FBTim only affects online bonding social capital, Gender, \#FBF and ComMT solely influence online bridging social capital. No significant relationships with online social capital could be found for FBMem, RLFBF, SimEB and SimHI.

As mentioned before, early investigations had found a positive relationship between the Facebook usage intensity and the two forms of social capital perceived in offline settings (Ellison et al., 2007; Steinfield et al., 2008), while follow-up studies (Kwon et al., 2013; Vitak et al., 2011) did not find an association with bonding social capital. Instead of lumping the daily time spent one the SNS, the attitude towards the SNS, and the number of friends on the SNS within one concept, we considered the influence of each variable individually. Facebook attitude (as in considering Facebook a part of one's daily life and being emotionally attached to the SNS) has the strongest effect on both online bonding and online bridging social capital, and in each case it is a positive one. Regarding online bonding social capital, it seems reasonable that users with a positive attitude towards Facebook find the SNS suitable to communicate with their close friends. As for bridging social capital, the feeling that one belongs to the Facebook community may reinforce a person's willingness to share updates and to keep in touch with people who are emotionally more distant. Disclosing personal details makes other people aware of a user, and it is one way to maintain and develop weaker ties and thus reinforces online bridging social capital (Ellison et al., 2007).

For both types of online social capital, the variable with the second strongest effect within the category of individual attributes is Age. Our findings indicate that older SNS users will have more online bridging social capital. Moreover, confirming the results of previous studies (Burke et al., 2010; Steinfield et al., 2009), older users tend to experience less online bonding social capital than younger users. Indeed, in 2012 more than half of the Facebook users in Germany were aged between 18 and 34 years (see Table 3). Hence, older users may be more reluctant or less able to communicate with close friends using the SNS, for example because many of their close friends do not have a Facebook account. On the other hand, older users may have a more diverse network in terms of socioeconomic background or age, which could explain their larger online bridging social capital.

We further find the daily time spent on the SNS to be positively related to online bonding, but unrelated to online bridging social capital. Amount of time being one indicator of tie strength (Granovetter, 1973), individuals may use the SNS to maintain closer ties via direct communication, e.g., by writing private messages, which tends to be more time-consuming than liking a status update (Burke et al., 2010). 
While we could not detect a significant relationship between Gender and online bonding social capital, our analysis shows that female participants tend to have lower levels of online bridging social capital. This relationship, however, is relatively weak compared to the previously-discussed effects. Women might select their SNS friends more cautiously or might not see a benefit in a high number of weak ties in their network, and may hence realise less bridging connections than men.

As can be seen in Table 4, all the constructs from the online social network category significantly related to online bonding social capital are significantly related to online bridging social capital, too. In addition, significant relationships can be established between \#FBF and ComMT and online bridging social capital. In line with the conceptualisation of (offline) social capital (Putnam et al., 1994) and the theory of tie strength (Granovetter, 1973), we find the fraction of close friends on Facebook to be positively related to online bonding social capital. In contrast to the conceptualisation, it is also (but much more weakly) positively related to online bridging social capital. In this regard, two explanations seem reasonable. First, close friends in the offline world are oftentimes individuals whom we meet and talk to frequently. Frequent contact is often related to living at the same place or to having a similar background, as in being related. Facebook, however, enables an easy and fast way to stay in touch with close friends who may for example live in a distant location or have a very different background. We can thus hypothesise that Facebook helps maintain ties with close friends who are different and who thus allow for access to non-redundant sets of resources and online bridging social capital. Second, the communication mechanisms on Facebook facilitate the easy creation of new contacts. For instance, people who have only met a few times and who have very different backgrounds may add each other on Facebook, follow each other's updates, and eventually become close friends.

Our analysis further shows that the fraction of SNS friends initially met on the SNS increases online bridging social capital but decreases online bonding social capital. In fact, such connections often result from playing Facebook games together, which is the main way to initiate new friendships on the SNS. As these games attract a heterogeneous community, the connections may be a source of online bridging social capital. Confirming the findings of one of the papers discussed in our literature review (Steinfield et al., 2009), we have been able to establish a negative relationship between the fraction of SNS friends initially met on the SNS and online bonding social capital. Representing a relatively small part of an individual's friendship network, the absolute number of close friends is likely to remain constant even if the overall size of the network increases due to new weak ties created through gaming, etc. In accordance with the findings in an offline setting (Burke et al., 2010), a higher number of Facebook friends is related to increases in online bridging social capital, as a larger network bears the chance of having access to more diverse resources. However, network size does not have an influence on online bonding social capital.

We further investigated the relationships between the composition of an individual's Facebook friendship network in terms of different variables related to socioeconomic status and online social capital (Australian Bureau of Statistics, 2004; Policy Research Initiative, 2005). According to the definition of bonding and bridging social capital (Putnam et al., 1994), the underlying assumption is that networks composed of homogeneous people are rich in bonding social capital, whereas networks of dissimilar people are a source of bridging social capital. We did not find similarity in terms of ethnic background or household income to be 
related to any of the two forms of social capital. These variables may be less important in online than in offline settings. Against our expectations, similarity in terms of education is positively related to both online bonding and bridging social capital. On the one hand, people may have close relationships with friends from school or university and use Facebook to communicate with them. On the other hand, similarity in educational background, as in a similar level of education, and online bridging social are not mutually exclusive. For instance, even if an individual's friendship network mostly includes people who have completed undergraduate studies, these friends can still have degrees in very different fields, and hence generate online bridging social capital. As expected, a higher proportion of Facebook friends with a different mother tongue is associated with increases in online bridging social capital. Facebook friends with other mother tongues are likely to be made when travelling or spending time abroad. While often not close, these connections can easily be maintained on Facebook.

The findings of this study need to be weighed against its potential limitations. We used an online panel, which comes with certain disadvantages (Göritz \& Moser, 2000). First, panel members are aware of being observed and have a great routine in participating in surveys, which may affect their way of answering questions. However, we have omitted those observations where the credibility was doubtful, e.g., due to patterns in the answers, or deviations of the answers from previously-known information. Moreover, all invited panel members decided themselves whether or not to answer our questionnaire. As a consequence, frequent Facebook users might be overrepresented in our sample. However, such selfselection effects are not a problem if they are related to the observed explanatory variables, such as FBTim. Furthermore, while our stratified sampling approach did not consider attributes such as the educational background of the participants, we made sure that the sample is representative for the Facebook users in terms of age and gender.

\section{Conclusions and Outlook}

In this article, we have analysed factors influencing online social capital, the validation of Williams' ISCS being a prerequisite for our investigation. Based on our statistical analysis we have found that all items in each of the two catalogues of items in Williams' ISCS indeed seem to measure the same latent construct. This suggests that Williams' ISCS can be used to validly measure online social capital. Similar to previous studies in offline settings, researchers could hence investigate the relationships between online bonding or bridging social capital, access to informational (and other types of) support, and further outcomes such as professional success or a healthy lifestyle.

As for the factors influencing online social capital, we have found significant influences of the variables Age, FBAtt, OnFBF, CloFBF and SimEd on both types of online social capital. While FBTim only affects online bonding social capital, Gender, \#FBF and ComMT solely influence online bridging social capital. No significant relationships with online social capital could be found for FBMem, RLFBF, SimEB and SimHI.

Our study has important implications for research and practice. In terms of research, we propose the following implications:

- In online settings, birds of a feature do not necessarily flock together. The similarity or dissimilarity of the members in one's online friendship network in terms of different sociodemographic attributes is not a very strong predictor of the different types of online social capital. Specifically, the influence of similarity in terms of ethnic 
background and household income is less pronounced than in offline settings. Furthermore, in contrast to previous studies performed in offline settings (Australian Bureau of Statistics, 2004; Policy Research Initiative, 2005), we found the similarity of the educational background to be positively related to bridging social capital.

- The antecedents of online bridging social capital differ from the ones of offline bridging social capital. While the factors influencing online bonding social capital seem to be similar to the ones identified in offline settings, online bridging social capital is influenced by other factors as compared to offline settings. In this regard, we found that four variables (i.e., Gender, Age, OnFBF, and RLFBF), which are not indicated to impact offline bridging social capital (Table 1), have a significant effect on online bridging social capital. Additionally, we found that the new variable CloFBF is also positively related to both types of online social capital, with a stronger impact on bonding social capital.

- Different types of online social capital are likely related to different outcomes. Like offline social capital, online bonding and bridging social capital may be associated with different types of resources and outcomes. While out of the scope of this paper, it is highly relevant to identify, characterise, and measure these resources, as well as to compare resources obtained based on different types of social capital offline and online. For instance, the association between online bonding social capital with informational support might be higher as compared to offline bonding social capital depending on the network of an individual's friends, e.g., the number of weak ties in their networks. Furthermore, it would be interesting to determine the "right" ratio between bonding and bridging social capital for different groups of individuals in order to achieve positive outcomes, e.g., concerning an individual's health (Durst, Viol, \& Wickramasinghe, 2013).

- Studies investigating online social capital can focus on fewer variables. As some of our variables turned out to not be related to online social capital, we will be able to reduce the number of variables in future studies, decreasing the burden of assessing these pieces of information.

Furthermore, we suggest the following practical implications:

- Creating and maintaining a positive SNS attitude is important. We found that FBAtt is the most influential predictor of both bonding and bridging online social capital. Hence, providers of SNS need to assure that the platform becomes embedded into the user's daily lives in order to achieve a positive attitude. Exemplary implications concern the design of the platform, such as providing a pleasant interface that is easy and fun to use. Moreover, platform providers should protect their users' privacy in order to create a trustful environment in which people are willing to share personal information. They also should have further measures in place, for example to prevent bullying and the spread of fake news, as well as to give users control over comments on their posted content.

- Online social platforms could contribute to balancing different types of resources accessible to users. Provided that it will be possible to measure resources accessible to users in the future, online social platforms could help users gain access to additional resources that they currently lack. For instance, users with high ratios of bonding social capital over 
bridging social capital could be increasingly prompted with information regarding events that are different from what they would normally see in their newsfeed. Besides contributing to breaking up echo chambers, platform vendors could address various societal issues (Durst et al., 2013), among them public health and education. For example, persons showing unhealthy eating habits could be provided with information regarding healthy food or sports activities in their newsfeed (Hacker, Wickramasinghe, \& Durst, 2017). Likewise, individuals with limited access to education could be prompted with information on online courses.

- Self-diagnostics may be a useful tool for interventions driven by individuals themselves. Being able to measure online social capital, platform vendors could implement tests that allow individuals to assess their own online social capital and the related resources that they can access. As a tool for self-reflection and benchmarking, such tests might help individuals to recognise the absence of certain types of resources in their networks and motivate them to do something about it. For instance, individuals with a lack of online bridging social capital could join additional groups or subscribe to additional updates to access more diverse information.

In terms of future research, we will investigate to what extent the process of data collection can be automated. Some of the variables (e.g., Gender, Age, and \#FBF) can directly be retrieved via the Facebook application as users log into the application via Facebook Login (Facebook, 2018b). For other variables, such as the duration of the Facebook membership and the daily time spent on Facebook, it is relatively easy to infer the values based on the data available. In terms of additional variables, data about a user's "likes" or events a user attended, which can be collected based on an application (Facebook, 2018a), could be used to determine a user's level of access to informational resources, for instance. Moreover, we will develop and apply data mining techniques that can be used to calculate values for the constructs that cannot simply be retrieved. For example, analysing tie strength, e.g., by identifying frequent communication partners, could help us determine the number of close friends, and certain usage patterns could allow conclusions regarding the attitude towards the SNS. Moreover, measures of homogeneity in terms of socioeconomic status and background can be determined if access to the data is granted. Our ultimate goal is to estimate online social capital based on a small set of related variables that can be collected automatically. Being able to do that would facilitate further analyses, concerning for example the dynamics of online social capital over time.

\section{Acknowledgements}

We would like to thank the GfK Verein (http://www.gfk-verein.org/) for supporting this study with regard to data collection via the GfK Online Panel.

\section{References}

Anheier, H., \& Kendall, J. (2002). Interpersonal trust and voluntary associations: examining three approaches. The British Journal of Sociology, 53(53), 343-362.

Antoci, A., Sabatini, F., \& Sodini, M. (2011). See you on Facebook! A framework for analyzing the role of computer-mediated interaction in the evolution of social capital. Munich. Retrieved 2015-04-30, from http://mpra.ub.uni-muenchen.de/29998/1/MPRApaper29998.pdf 
Australian Bureau of Statistics. (2004). Measuring social capital: An Australian framework and indicators (ABS Information Paper No. 1378.0). Australian Bureau of Statistics. Canberra, Australia. Retrieved 2018-01-24, from http://www.ausstats.abs.gov.au/Ausstats/free.nsf/Lookup/13C0688F6B98DD45CA256E 360077D526/\$File/13780_2004.pdf

Avenarius, C. B. (2010). Starke und schwache Beziehungen. In C. Stegbauer \& R. Häußling (Eds.), Handbuch Netzwerkforschung (pp. 99-111). Wiesbaden. VS Verlag für Sozialwissenschaften.

Bohn, A., Buchta, C., Hornik, K., \& Mair, P. (2014). Making friends and communicating on Facebook. Implications for the access to social capital. Social Networks, 37, 29-41.

Boomsma, A. (1982). The robustness of LISREL against small sample sizes in factor analysis models. In K. G. Jöreskog \& H. Wold (Eds.), Systems under indirect observation. Causality, structure, prediction. Part I (pp. 149-173). Amsterdam. North-Holland.

Brandtzæg, P. B., \& Nov, O. (2010). Facebook use and social capital - A longitudinal study. In Proceedings of the Fifth International AAAI Conference on Weblogs and Social Media (pp. 454457).

Brooks, B., Hogan, B., Ellison, N., Lampe, C., \& Vitak, J. (2014). Assessing structural correlates to social capital in Facebook ego networks. Social Networks, 38, 1-15.

Browne, M. W., \& Cudeck, R. (1992). Alternative ways of assessing model fit. Sociological Methods \& Research, 21 (2), 230-258.

Burke, M., Kraut, R., \& Marlow, C. (2011). Social capital on Facebook. Differentiating uses and users. In Proceedings of the 29th International Conference on Human Factors in Computing Systems - CHI '11 (pp. 571-580).

Burke, M., Marlow, C., \& Lento, T. (2010). Social network activity and social well-being. In Proceedings of the 28th International Conference on Human Factors in Computing Systems CHI'10 (pp. 1909-1912).

Christakis, N., \& Fowler, J. H. (2013). Social contagion theory: Examining dynamic social networks and human behavior. Statistics in Medicine, 32 (4), 556-77.

Chua, C., Lim, W., \& Soh, C. (2012). Enacting clan control in complex it projects. A social capital perspective. MIS Quarterly, 36 (2), 577-600.

Czech, C. (2012). Facebook-Statistiken für Deutschland. Retrieved 2012-04-15, from http://neunzehn80.de/facebook-statistik/

Durst, C., Viol, J., \& Wickramasinghe, N. (2013). Online social networks, social capital and health-related behaviours: A state-of-the-art analysis. Communications of the Association for Information Systems, 32, 134-158.

Ellis, P. D. (2010). The Essential Guide to Effect Sizes. Statistical Power, Meta-Analysis, and the Interpretation of Research Results. Cambridge. Cambridge University Press.

Ellison, N., Lampe, C., Steinfield, C., \& Vitak, J. (2010). With a little help from my friends. Social Network Sites and social capital. In Z. Papacharissi (Ed.), A networked self. Identity, community and culture on social network sites (pp. 124-145). New York. Routledge. 
Ellison, N., Steinfield, C., \& Lampe, C. (2007). The benefits of Facebook "friends." Social capital and college students' use of online social network sites. Journal of Computer-Mediated Communication, 12 (4), 1143-1168.

Ellison, N., Steinfield, C., \& Lampe, C. (2011). Connection strategies. Social capital implications of Facebook-enabled communication practices. New Media \& Society, 13 (6), 873-892.

Ellison, N., Vitak, J., Gray, R., \& Lampe, C. (2014). Cultivating social resources on social network sites. Facebook relationship maintenance behaviors and their role in social capital processes. Journal of Computer-Mediated Communication, 19 (4), 855-870.

Facebook. (2018a). Permissions Reference - Facebook Login. Retrieved 2018-01-24, from https://developers.facebook.com/docs/facebook-login/permissions

Facebook. (2018b). Permissions with Facebook Login. Retrieved 2018-01-24, from https://developers.facebook.com/docs/facebook-login/permissions/overview

Fox, J. (2006). Structural equation modeling with the sem package in R. Structural Equation Modeling, 13 (3), 465-486.

Göritz, A. S., \& Moser, K. (2000). Repräsentativität im Online Panel. Der Markt, 39 (4), 156-162.

Granovetter, M. S. (1973). The strength of weak ties. The American Journal of Sociology, 78 (6), 1360-1380.

Hacker, J., Wickramasinghe, N., and Durst, C. 2017. "Can Health 2.0 Address Critical Healthcare Challenges? Insights from the Case of How Online Social Networks Can Assist in Combatting the Obesity Epidemic," Australasian Journal of Information Systems (21).

Hyyppä, M. T. (2010). Healthy Ties. Dordrecht. Springer Netherlands.

Jung, Y., Gray, R., Lampe, C., \& Ellison, N. (2013). Favors from Facebook friends. Unpacking dimensions of social capital. In Proceedings of the 31st international conference on Human factors in computing systems - CHI '13 (pp. 11-20).

Kneidinger, B. (2010). Facebook und Co. Wiesbaden. VS Verlag für Sozialwissenschaften.

Kwon, M.-W., D'Angelo, J., \& McLeod, D. M. (2013). Facebook use and social capital. To bond, to bridge, or to escape. Bulletin of Science, Technology \& Society, 33 (1-2), 35-43.

Lee, E., Kim, Y. J., \& Ahn, J. (2014). How do people use Facebook features to manage social capital? Computers in Human Behavior, 36, 440-445.

Lin, N. (2001a). Building a network theory of social capital. In N. Lin, K. S. Cook, \& R. Burt (Eds.), Social capital. Theory and research (pp. 3-29). New Brunswick. Transaction Publishers.

Lin, N. (2001b). Social Capital. A Theory of Social Structure and Action. Cambridge. Cambridge University Press.

Marmot, M., \& Wilkinson, R. G. (Eds.). (2005). Social Determinants of Health (2nd ed.). Oxford University Press.

Marsh, H. W., Hau, K.-T., Balla, J. R., \& Grayson, D. (1998). Is more ever too much? The number of indicators per factor in confirmatory factor analysis. Multivariate Behavioral Research, 33 (2), 181-220. 
Policy Research Initiative. (2005). Measurement of social capital. Retrieved 2018-01-24, from http://www.ocol-clo.gc.ca/sites/default/files/Measurement_of_Social_Capital.pdf

Portes, A. (1998). Social capital. Its origins and applications in modern sociology. Annual Review of Sociology, 24 (1), 1-24.

Putnam, R. D. (2001). Bowling Alone. New York. Simon \& Schuster.

Putnam, R. D., Leonardi, R., \& Nanetti, R. Y. (1994). Making Democracy Work. Civic Traditions in Modern Italy. Princeton. Princeton University Press.

R Core Team. (2018). R. A language and environment for statistical computing. Vienna. Retrieved 2018-01-24, from http://www.R-project.org/

Rostila, M. (2011). A resource-based theory of social capital for health research. Can it help us bridge the individual and collective facets of the concept? Social Theory $\mathcal{E}$ Health, 9 (2), 121.

Schlittgen, R. (2009). Multivariate Statistik. München. Oldenbourg Verlag.

Sörbom, D. (1989). Model modification. Psychometrika, 54 (3), 371-384.

Steiger, J. H. (1989). EzPATH. Casual modeling [Computer software manual]. Evanston.

Steinfield, C., DiMicco, J. M., Ellison, N. B., \& Lampe, C. (2009). Bowling online. In Proceedings of the fourth international conference on communities and technologies - CET '09 (pp. 245-254).

Steinfield, C., Ellison, N., \& Lampe, C. (2008). Social capital, self-esteem, and use of online social network sites. A longitudinal analysis. Journal of Applied Developmental Psychology, 29 (6), 434-445.

Stone, W., \& Hughes, J. (2002). Measuring social capital. Towards a standardised approach. In 2002 Australasian Evaluation Society International Conference. Wollongong, Sydney. Retrieved 2018-01-24, from http://evaluationcanada.ca/distribution/20021030_stone_wendy_hughes_jody.pdf

Van Der Gaag, M., \& Webber, M. (2008). Measurement of individual social capital. In I. Kawachi, S. Subramanian, \& D. Kim (Eds.), Social capital and health (pp. 29-49). New York. Springer.

Vitak, J., Ellison, N., \& Steinfield, C. (2011). The ties that bond. Re-examining the relationship between Facebook use and bonding social capital. In Proceedings of the 44th Hawaii International Conference on System Sciences (pp. 1-10).

von Auer, L. (2013). Ökonometrie (6th ed.). Berlin. Springer Verlag.

Westland, J. C. (2010). Lower bounds on sample size in structural equation modeling. Electronic Commerce Research and Applications, 9 (6), 476-487.

Westland, J. C. (2012). Erratum to 'lower bounds on sample size in structural equation modeling'. Electronic Commerce Research and Applications, 11 (4), 445.

Williams, D. (2006). On and off the 'net. Scales for social capital in an online era. Journal of Computer-Mediated Communication, 11 (2), 593-628.

Yoder, C., \& Stutzman, F. (2011). Identifying social capital in the Facebook interface. In Proc. SIGCHI Conference on Human Factors in Computing Systems (CHI 2011) (pp. 585-588). 
Young, K. (2011). Social ties, social networks and the Facebook experience. International Journal of Emerging Technologies and Society, 9 (1), 20 - 34. 


\section{Appendices}

\section{Appendix 1. German version of the online questionnaire}

\section{A Soziodemographie I}

\section{S1 Quotenfrage}

Zunächst möchten wir Sie bitten, einige Angaben zu Ihrer Person zu machen.

Sind Sie männlich oder weiblich?

- männlich

- weiblich

\section{S2 Quotenfrage}

Wie alt sind Sie?

- (Bitte eintragen) Jahre

\section{S3 Screenerfrage}

Besitzen Sie ein Facebook-Konto?

- Ja

- Nein

\section{S4 Momentaufnahme des Facebook-Netzwerkes}

Für unsere Studie benötigen wir eine Momentaufnahme Ihres Facebook-Netzwerkes. Klicken Sie hierzu bitte auf [WEITER] und akzeptieren Sie die Genehmigungsanfragen der FacebookAnwendung.

\section{B Internetnutzung und Facebook}

\section{Allgemeine Informationen}

\section{I1}

Bitte machen Sie im nächsten Abschnitt Angaben zu Ihrer Internet- und Facebook-Nutzung. Wie viel Zeit verbringen Sie durchschnittlich pro Tag im Internet?

- Weniger als $10 \mathrm{~min}$

- 11-30 min

- 31-60 min

- $1-2 \mathrm{~h}$

- 2-3 h

- mehr als $3 \mathrm{~h}$ 


\section{I2}

Wie lange sind Sie schon Mitglied auf Facebook?

- 6 Monate oder weniger

- 6 Monate bis $1 \mathrm{Jahr}$

- 1-2 Jahre

- 2-3 Jahre

- 3-4 Jahre

- mehr als 4 Jahre

I3

Wie viel Zeit verbringen Sie durchschnittlich pro Tag auf Facebook?

- Weniger als $10 \mathrm{~min}$

- 11-30 min

- $31-60 \mathrm{~min}$

- $1-2 \mathrm{~h}$

- $2-3 \mathrm{~h}$

- mehr als $3 \mathrm{~h}$

I4

Im Folgenden interessieren wir uns für Ihre Einstellung zu Facebook. Bitte wählen Sie jeweils die für Sie am besten passende Antwortkategorie aus. 1 bedeutet „trifft überhaupt nicht zu“ und 5 bedeutet „trifft voll und ganz zu“. Mit den Werten dazwischen können Sie Ihre Meinung abstufen.

- Facebook ist Teil meines täglichen Lebens.

- Ich bin stolz, wenn ich jemandem sagen kann, dass ich auf Facebook bin.

- Facebook ist zu einem fixen Bestandteil meines täglichen Lebens geworden.

- Ich fühle mich von der Realität abgeschnitten, wenn ich längere Zeit nicht auf Facebook eingeloggt war.

- Ich fühle mich als Teil der Facebook-Gemeinschaft.

- Ich fände es schade, wenn es Facebook nicht mehr gäbe.

\section{Freundesnetzwerk auf Facebook}

\section{I5}

Mit den nachfolgenden Fragen möchten wir nun etwas mehr über Ihre Facebook-Freunde erfahren.

Wie viele Facebook-Freunde haben Sie im Moment:

- _ Freunde 
I6

Denken Sie an Ihr Freundesnetzwerk auf Facebook. Wie viele Ihrer Facebook-Freunde haben Sie online kennengelernt?

- keinen

- wenige

- etwa die Hälfte

- die meisten

- alle

- Keine Angabe

$\mathbf{I}$

Denken Sie nun an Ihre Freunde aus dem realen Leben. Mit wie vielen dieser Freunde sind Sie auch auf Facebook verbunden?

- keinem

- wenigen

- etwa der Hälfte

- den meisten

- allen

- Keine Angabe

\section{I8}

Denken Sie an Ihr Freundesnetzwerk auf Facebook. Wie viele Ihrer Facebook-Freunde würden Sie als engere Freunde bezeichnen?

- keinen

- wenige

- etwa die Hälfte

- die meisten

- alle

- Keine Angabe

I9

Denken Sie an die Personen, mit denen Sie auf Facebook verbunden sind. Wie viele Ihrer Facebook-Freunde sprechen die gleiche Muttersprache wie Sie?

- keiner

- wenige

- etwa die Hälfte

- die meisten

- alle

- Keine Angabe 


\section{I10}

Wie viele Ihrer Facebook-Freunde haben einen ähnlichen ethnischen Hintergrund wie Sie?

- keiner

- wenige

- etwa die Hälfte

- die meisten

- alle

- Keine Angabe

\section{I11}

Wie viele Ihrer Facebook-Freunde haben ein ähnliches Bildungsniveau wie Sie?
- keiner
- wenige
- etwa die Hälfte
- die meisten
- alle
- Keine Angabe

\section{$\mathbf{I 1 2}$}

Wie viele Ihrer Facebook-Freunde haben ein ähnlich hohes Haushaltseinkommen wie Sie?

- keiner

- wenige

- etwa die Hälfte

- die meisten

- alle

- Keine Angabe

\section{I13}

Bitte beantworten Sie im nächsten Abschnitt einige allgemeine Fragen zu Ihrem Freundesnetzwerk auf Facebook. Bitte wählen Sie die jeweils auf Sie am besten passende Antwortkategorie aus. 1 bedeutet ,trifft überhaupt nicht zu“ und 5 bedeutet „trifft voll und ganz zu“. Mit den Werten dazwischen können Sie Ihre Meinung abstufen.

\section{Block 1}

- Das Kommunizieren mit Personen auf Facebook weckt meine Neugier für andere Orte in der Welt.

- Ich verbringe meine Zeit gern damit, gemeinschaftliche Aktivitäten auf Facebook zu unterstützen.

- Auf Facebook lerne ich ständig neue Leute kennen. 


\section{Block 2}

Auf Facebook gibt es ...

- ... mehrere Personen, denen ich meine Probleme anvertraue und die mir weiterhelfen können.

- ...jemanden, den ich um Rat fragen kann, wenn ich sehr wichtige Entscheidungen treffen muss.

- ... niemanden, mit dem ich bereitwillig über intime persönliche Probleme spreche.

- ... mehrere Personen, mit denen ich reden kann, wenn ich mich einsam fühle.

\section{Block 3}

Durch den Austausch mit Personen auf Facebook...

- ... fühle ich mich als Teil einer größeren Gemeinschaft.

- ... fühle ich mich mit dem großen Ganzen verbunden.

- ... wird mir bewusst, dass alle Menschen auf der Welt miteinander verbunden sind.

- ... interessiere ich mich für Dinge, die außerhalb meiner Stadt geschehen.

- ... möchte ich neue Sachen ausprobieren.

- ... interessiere ich mich dafür, was Leute, die anders als ich sind, denken.

- ... lerne ich neue Leute kennen, mit denen ich mich unterhalten kann

\section{Block 4}

Die Personen, mit denen ich mich auf Facebook austausche, würden...

- ... ihr letztes Geld mit mir teilen.

- ... mir dabei helfen, ein Unrecht zu bekämpfen.

- ... ihren Ruf für mich aufs Spiel setzen.

- ... mir als Referenz für einen potenziellen neuen Arbeitgeber dienen.

\section{Block 5}

Ich kenne auf Facebook...

- ... jemanden, an den ich mich im Notfall wenden könnte, um mir 500 Euro zu leihen.

- ...niemanden so gut, dass ich ihn etwas für mich Wichtiges machen lassen würde.

\section{Soziodemographie II}

\section{SA1}

Welches ist der höchste von Ihnen erreichte Schulabschluss?

- bin noch in der Schulausbildung

- Hauptschule/Volksschule ohne abgeschlossene Lehre (8-klassige Schule)

- Hauptschule/Volksschule mit abgeschlossener Lehre (8-klassige Schule)

- Mittel-/Real-/Fach-/Handelsschule ohne Abitur (10-klassige Polytechnische Oberschule)

- Abitur/Hochschulreife (12-klassige Erweiterte Oberschule)

- abgeschlossenes Studium (Universität, Fachhochschule, Akademie) 


\section{SA2}

Welche der folgenden Aussagen trifft auf Ihre derzeitige Berufstätigkeit/ Ausbildung zu? Ich bin...

- voll berufstätig

- teilweise berufstätig

- vorübergehend nicht berufstätig/ arbeitslos

- nicht (mehr) berufstätig (in Rente/ Pension/ Hausfrau/ Hausmann)

- in Berufsausbildung/ Lehre/ Wehrpflicht/ Zivildienst/ in Schulausbildung (Schüler)

- in Hochschulausbildung (Student)

- nicht berufstätig und nie berufstätig gewesen 


\section{Appendix 2. English version of the online questionnaire}

\section{A Sociodemographic information I}

\section{S1}

First, we would like to ask you to give some information about yourself.

Are you male or female?

- Male

- Female

\section{S2}

How old are you? (Please fill in your age in years)

- _ years

\section{S3}

Do you have a Facebook account?

- Yes

- No

\section{S4 Snapshot of your Facebook network}

For this study, we need a snapshot of your Facebook network. To give us access to your Facebook network, please click [NEXT] and accept the permission requests of the application.

\section{$B$ Internet usage and Facebook}

\section{General information}

\section{I1}

In this section, we will ask you to provide information about your Internet and Facebook usage. On average, how much time, approximately, do you spend on the Internet per day?

- Less than 10 minutes

- 11-30 minutes

- 31-60 minutes

- 1-2 hours

- 2-3 hours

- More than 3 hours 
I2

For how long have you been a member of the Facebook community?

- 6 months or less

- 6 months -1 year

- 1-2 years

- 2-3 years

- 3-4 years

- More than 4 years

\section{I3}

On average, how much time, approximately, do you spend on Facebook per day?

- Less than 10 minutes

- 11-30 minutes

- 31-60 minutes

- 1-2 hours

- 2-3 hours

- More than 3 hours

\section{I4}

In the following section, we are interested in your attitude towards Facebook. For each statement, please select the most suitable answer from your point of view. Answers range from "strongly disagree" (1) to "strongly agree" (5).

- Facebook is part of my everyday activity.

- I am proud to tell people I'm on Facebook.

- Facebook has become part of my daily routine.

- I feel out of touch when I haven't logged onto Facebook for a while.

- I feel I am part of the Facebook community.

- I would be sorry if Facebook shut down.

\section{Network of friends on Facebook}

\section{I5}

With the following questions, we would like to find out a bit more about your Facebook friends.

How many Facebook friends do you currently have?

- _ Facebook friends 
I6

Think of your network of Facebook friends. How many of your Facebook friends did you meet online?

- None

- A few

- About half

- Most

- All

- (no answer)

\section{I7}

Now, please think of your real-life friends. With how many of your real-life friends are you connected on Facebook?

- None

- A few

- About half

- Most

- All

- (no answer)

I8

Think of your network of Facebook friends. How many of your Facebook friends do you consider close friends?

- None

- A few

- About half

- Most

- All

- (no answer)

19

Think of the persons you are connected with on Facebook. How many of your Facebook friends share your mother tongue?

- None

- A few

- About half

- Most

- All

- (no answer) 


\section{I10}

How many of your Facebook friends have an ethnic background that is similar to yours?

- None

- A few

- About half

- Most

- All

- (no answer)

\section{I11}

How many of your Facebook friends have an educational background that is similar to yours?

- None

- A few

- About half

- Most

- All

- (no answer)

\section{I12}

How many of your Facebook friends have a household income that is similar to yours?

- None

- A few

- About half

- Most

- All

- (no answer)

\section{I13}

In the following section, we will ask you questions about your network of Facebook friends. Answers range from "strongly disagree" (1) to "strongly agree" (5). For each question, please select the most appropriate answer.

\section{Part 1}

- Talking with people on Facebook makes me curious about other places in the world.

- I am willing to spend time to support general community activities on Facebook.

- On Facebook, I come in contact with new people all the time.

\section{Part 2}

On Facebook, there ...

- ... are several people I trust to help solve my problems.

- $\quad . .$. is someone I can turn to for advice about making very important decisions.

- $\quad . .$. is no one that I feel comfortable talking to about intimate personal problems. 
- ... are several people I can talk to when I feel lonely.

\section{Part 3}

Interacting with people on Facebook ...

- ... makes me feel like part of a larger community.

- ... makes me feel connected to the bigger picture.

- ... reminds me that everyone in the world is connected.

- ... makes me interested in things that happen outside of my town.

- ... makes me want to try new things.

- ... makes me interested in what people unlike me are thinking.

- ... gives me new people to talk to.

\section{Part 4}

The people I interact with on Facebook would ...

- ... share their last dollar with me.

- ... help me fight an injustice.

- ... put their reputation on the line for me.

- $\quad .$. be good job references for me.

\section{Part 5}

- If I needed an emergency loan of $\$ 500$, I know someone on Facebook I can turn to.

- I do not know people on Facebook well enough to get them to do anything important.

\section{Sociodemographic information II}

\section{SA1}

Finally, we would like to know a bit about your educational background.

What is your highest level of educational achievement?

- I am still attending school.

- Secondary modern school (year 5 to year 9) without completed apprenticeship training

- Secondary modern school (year 5 to year 9) with completed apprenticeship training

- Secondary school (year 5 to year 10) without general qualification for university entrance

- General qualification for university entrance

- Completed university degree (university, university of applied sciences, university of cooperative education)

\section{SA2}

Which of the following statements describes best your current occupation?

I am ...

- ... employed full-time

- ... employed part-time 
- ... temporarily not employed / unemployed

- ... not employed anymore (e.g., retired)

- ... doing a vocational training / apprenticeship / military service / civilian service / attending school

- ... a university student

- ... not employed, and I have never been employed

Copyright: ( 2018 Grottke, Hacker \& Durst. This is an open-access article distributed under the terms of the Creative Commons Attribution-NonCommercial 3.0 Australia License, which permits non-commercial use, distribution, and reproduction in any medium, provided the original author and AJIS are credited.

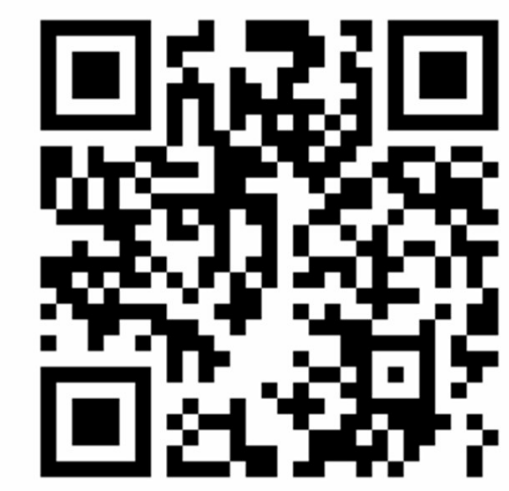

